\title{
Indices of socio-emotional wellbeing of youth: evaluation and directions of improvement
}

\author{
Pavel Kislyakov ${ }^{1, \mathrm{a}}$, Elena Shmeleva ${ }^{2}$, Olga Silaeva $^{2}$, Natalia Belyakova ${ }^{1}$ and Valery Kartashev ${ }^{1}$ \\ ${ }^{1}$ Russian State Social University, 129226, Wilhelm Pieck str., 4, Moscow, Russia \\ ${ }^{2}$ Ivanovo State University, 155900, Kooperativnaya str., 24, Shuya, Russia
}

\begin{abstract}
Research objective: The aim of this work is to evaluate the socio-emotional wellbeing of youth and to specify their directions of improvement. Research methods: Theoretical analysis of works on educational psychology and social psychology devoted to the issues of the socio-emotional wellbeing and psychological safety of students; conducting testing of students. Research results: Basing on the analysis of the theoretic and methodological material we defined and described personal qualities of students, which determine socio-emotional (psychosocial) well-being and which are indices of social-psychological safety of education environment. These indices are as follows: communication skills, social tolerance, creativity. The conducted investigation allowed us to reveal positive correlation connections between the level of subjective well-being and formedness of personal qualities, which define the socio-emotional wellbeing of students. The authors have concluded that it is necessary to improve the organization of the educational process in order to ensure the socio-emotional wellbeing of students and social safety of society as a whole To prevent the threats, the necessity of creation of a safe educational environment is grounded which should comprise a tolerant environment, and psychologically comfortable environment excluding any violence and requiring the relevant professional training of teachers and education personnel.
\end{abstract}

\section{Introduction}

Nowadays the problem of the socio-emotional wellbeing of a person and the society has become one of the most pressing. The importance of the educational system in the opposition to negative social processes (drug addiction, alcoholism, youth delinquency, religious and national extremism, homelessness, socially determined diseases, etc.) and in the formation of healthy and safe mode of life of the society is confirmed by the strategic directions of the international and national policy. The educational psychology, in revealing the vagueness of the modern cultural-historical, political, and psychopedagogical situation, points to the developing resource of psycho-pedagogical science in human society; the perfection of its status among socio-cultural, psychophysiological, and other educational reserves.

The youth often spend in an educational establishment even more time than in other social environments. That is why the degree of impact of this microsocium on the socialization, development, health and behavior of a young man is inestimable. A number of authors indicate that the socio-emotional wellbeing of students should be the conceptual framework for education reforms $[1,2,3]$.
Enviromental psychology shows that the personality development occurs in a dialectical mutual transitions "subject - environment": environment influences on human feelings and behavior, and the same feelings and behavior affect the same environment [4].

There are a lot of risks and threats facing any education environment.

The major premises for the emergence of social threats in an educational institution are the following:

- the increase in social tension caused by the economic and financial crisis, an increasing number of stressful situations and psychogenic disorders in families and in educational institutions;

- influence of criminogenic factors;

- social unrooting of children and teenagers, the lack of psychological support provided by adults;

- the lack of legal culture and the necessary knowledge about psychology on the part of some teachers, authorities and the general public.

- the destruction or lack of effective methods of the creation of spiritual, moral, social and economical foundations needed for uniting the society;

- a decline in the general culture in the education system, discontinuity of social, cultural and national traditions;

- weakening of social control over unlawful conduct; 
- a reduction in the opportunities for children's and teenagers' creative activities conforming to the relevant moral and ethical standards, which results in crime and anti-social behavior (from vandalism to delinquency and extremism);

- aggressiveness of infomedia, violence scenes on $\mathrm{TV}$, in mass media, in the Internet.

All these phenomena create such new problems as:

- a climate of fear and insecurity;

- interruption of education process in some educational institutions;

- depreciation of democratic values in the minds of students.

Nowadays, the challenge of social security and safety persists as it is not easy to attract the personnel and the students of an educational institution to address the problems associated with safety and security, to protect person or property against offences, and to maintain favorable social-psychological environment and public order in the educational institution as well as to ensure occupational safety and health protection of both the personnel and the students $[5,6]$.

Issue of psychological safety or a culture of one in interactions within an educational environment seems extremely important. Multi-aspect approach to security enables to consider security as a condition, which provides fundamental securitization of personality and makes it possible to consider personality security condition as a social and normative ideal [7].

In the course of factor analysis of empiric material and the analysis of systematized theoretical and methodological material concerning the problem of socio-emotional wellbeing of young people (university students) we have deduced that the socio-emotional (psychosocial) wellbeing of students is characterised by such personal qualities as creativity, social tolerance, communication skills [8]. The level of socio-emotional wellbeing is directly relevant to the assessment of the social environment.

\section{Materials and methods}

In order to evaluate the above-mentioned indices of socio-emotional wellbeing we have developed a set of diagnostic tools which includes standardized methods. To diagnose creativity we have used a modified test "Creativity" (N.F. Vishnjakova. Diagnostics creative potential. Psychological tests "creative potential". Minsk, 1999). The test allows revealing the level of creative skills of a personality and making a psychological creative profile. While evaluating creativity the students were asked to evaluate their personal qualities: originality, curiosity, imagination, intuition, creative thinking, emotionality and empathy, sense of humor, creative attitude to the profession. To diagnose the general level of the social tolerance of students we used the express-checklist "Tolerance index" (G.U. Soldatova, L.A. Shaygerova \& T.Y. Prokofieva. Psychodiagnostics tolerance of the person. Moscow, 2008). Three subscales of the checklist were aimed at diagnostic of such aspects of tolerance as ethnic tolerance (attitude to the people of another race and ethnic group), social tolerance (attitude to the minorities, the poor, mentally handicapped people), tolerance as a feature of a personality (readiness to the constructive settlement of conflicts and productive cooperation). In order to diagnose communication skills and abilities we have used the Section "Communication abilities" of the checklist "Diagnostic of communication and organizational abilities" (KOS-2) (N.P. Fetiskin, V.V. Kozlov \& G.M. Manuilov. A socio-psychological diagnosis of development of the personality and small groups. Moscow, 2002). The checklist measures communication skills (the ability to establish business and friendly contacts with people clearly and quickly, the intention to broaden contacts, participation in group events, the ability to influence people, the intention to take the initiative etc.). The investigation of the degree of the students' subjective well-being was conducted using the "Scale of subjective well-being" method, created by French psychologists Perrudet-Badoux, Mendelsohn and Chiche. The scale consists of 17 items which are divided into 6 clusters: tension and sensibility; qualities which accompany main mental semiology such as depression, drowsiness, a short span of attention etc.; change of mood; significance of social environment; self-estimation of health; degree of satisfaction by the everyday activity. The test allows revealing the presence and depth of emotional discomfort of a personality, and the answers to certain questions can help to reveal areas of a significant tension or conflict.

\section{Results and discussion}

The conducted investigation in the Shuiskiy department of the Ivanovo State University (the total number of respondents was approximately 700 people) allowed us to evaluate the degree of students' formedness of personally important qualities, which define the level of socio-emotional wellbeing. Test results are presented in figures 1 and 2 .

The correlative analysis conducted with the help of Pirson correlations showed strong $(\mathrm{p} \leq 0.01)$ straight correlation connections between the level of subjective wellbeing and formedness of personal qualities (indices of the socio-emotional wellbeing) (Table 1).

Natural feeling of wellbeing (safety) is one of the basic feelings of a normal person. Children study better when they are safe/happy. E. Huebner and R. Gilman associate psychological prosperity of the learners with life satisfaction and ability to control stress [9]; S. Suldo, E. Shaffer and K. Riley - with high emotional regulation and academic abilities [10].

The studies that have been carried out in recent years show that about $70 \%$ of students are in the state of steady stress that appear to be the reason of neurosis and somatic illnesses. The increase of neuro-emotional stress, psycho-emotional tension, neurotic reactions of students have a negative impact on their relations. 


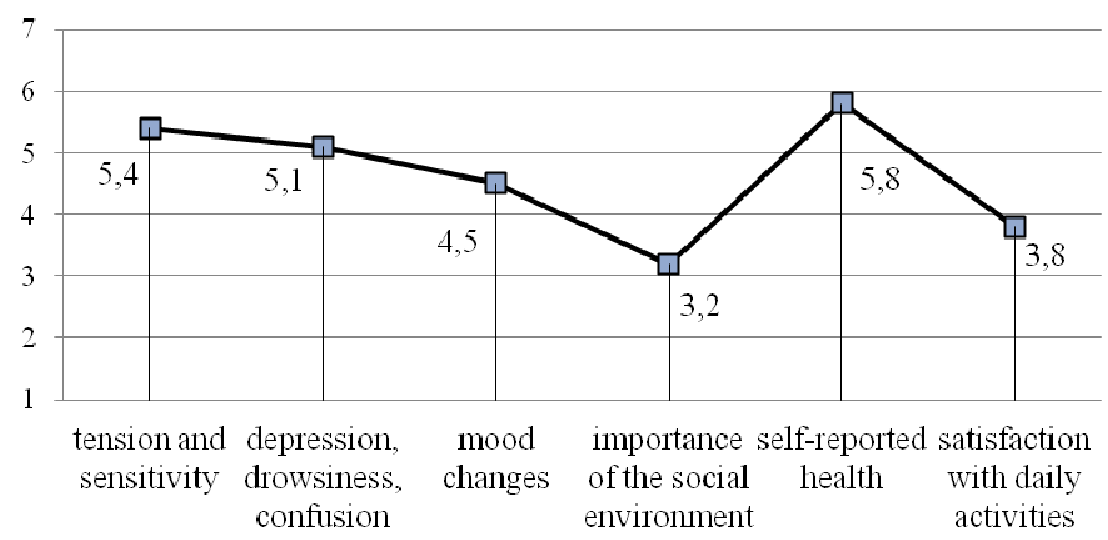

Fig. 1. Level of students' subjective wellbeing clusters.

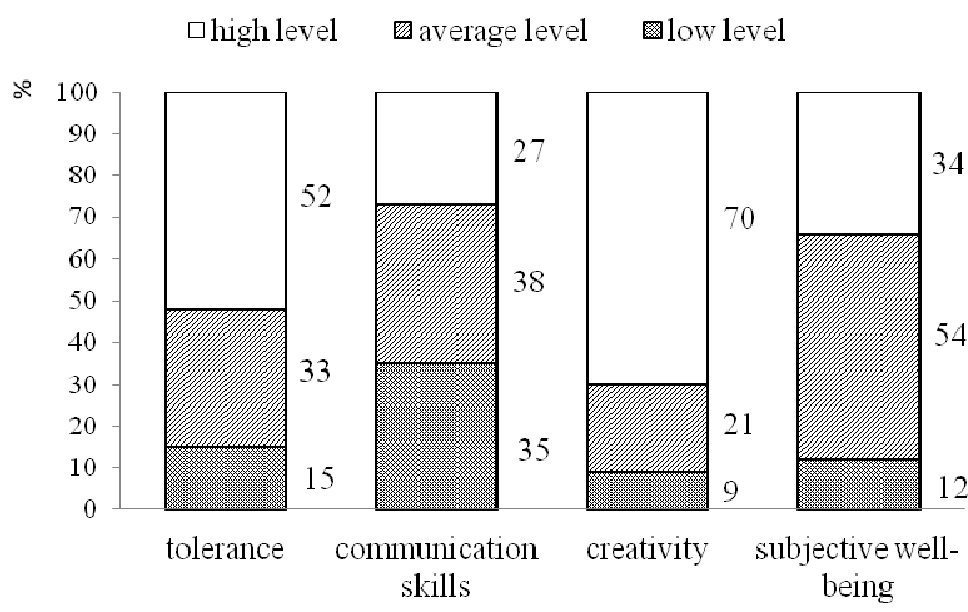

Fig. 2. Personal indices which define the state of the socio-emotional wellbeing.

Table 1. Correlation between the indices of socio-emotional wellbeing.

\begin{tabular}{|l|c|c|c|c|}
\hline \multirow{2}{*}{ Indices } & Subjective well-being & Social tolerance & Communication skills & Creativity \\
\cline { 2 - 5 } & \multicolumn{4}{|c|}{ Correlations } \\
\hline Subjective well-being & 1 & 0.625 & 0.714 & 0.608 \\
\hline Social tolerance & 0.625 & 1 & 0.454 & 0.294 \\
\hline Communication skills & 0.714 & 0.454 & 1 & 0.531 \\
\hline Creativity & 0.608 & 0.294 & 0.531 & 1 \\
\hline
\end{tabular}

From the health psychology perspective a normal personality is mentally stable (including stress resistance) when he/she is able to support his/her own reliability and to stand against the outward influences, to overcome the resistance of the outward conditions, to struggle against hindrances and finally succeed in hitting the targets. Moreover, a young person must be ready to prevent his/her stress states in extreme situations of social characters, which implies the necessity of special psychological preparation for social and extreme types of activity.

I.A. Baeva defines the psychological safety and wellbeing as such a state of a social environment which is free from any manifestation of violence in interactions and is able to respond to the need for open communication. Such a social environment creates the particular importance of the environment and protects the psychological health of a person [11].

The psychologically safe social environment contributes to the level of development of personal qualities and social competences relating to living in a multi-cultural society: understanding the differences, showing mutual tolerance and respect, being able to find a common language with people from different cultures and religions. The development of a humane society is impossible without the mutual respect and tolerance of people, without the development of religious culture and knowledge. The recognition of the dignity and worth of 
all persons shall be the key prerequisite not only for successful integration, but also for survival in today's world. However, one should remember that tolerance is not the passive acceptance of the opinion, sights and other people's behavior, but the active moral position and psychological readiness to the positive interaction between people, based on effective morality and in accordance with the law. A tolerant environment can be characterized by the atmosphere of non-violence, mutual support and tolerant approach to interaction, by the ability of different people to understand and accept one another regardless of diversity of belief, culture and language, by the democratic leadership style. It promotes morality, legal culture as well as the culture of tolerant communication and tolerant behavior, the culture of selfaffirmation and self-actualization [12].

At the micro level, the potential threats to socioemotional wellbeing occur in direct communication with other people. Such threats include abuse, manipulation, unstable social ties. The presence of such necessity as communication need makes communication and a proper attitude towards people one of the primary values. No doubt that the things a person says and the manner in which $\mathrm{s} / \mathrm{he}$ does it as $\mathrm{s} /$ he delivers his/her speech, have impact not only on successful assimilating of knowledge, but also on health, especially mental. Recently in the youth environment, the use of fowl words and profanities has dramatically increased. People who frequently use profanities, already have defects in mental health; he/she degrades as a person. In this regard, in an educational institution, special attention should be directed to the enhancement of the speech standards of a person.

To ensure socio-emotional wellbeing, the student should possess the following communicative skills.

- The ability to personality-oriented, trust-based cooperation, including goodwill and courtesy.

- The skills of democratic communication, including the ability to listen, to understand, to convince, to explain, to argue, etc.

- The skills of high speech standards, including clarity, literate language

- The ability to maintain emotional balance, prevent, and resolve conflicts in a constructive way, including the ability to cooperate, to reach compromise.

- The ability to develop a strategy, tactics and techniques of active interaction with people, to organize joint activities for the achievement of certain societal goals.

It is very important that a student should not only know the psychological essence of socio-emotional wellbeing, but be able to use the methods of its providing in praxis, to creatively apply them in any situations. Cognition of oneself, one's own abilities and skills, self-realization, creation of social-psychological environment of one's own living are always a creative process which takes place in the creative environment contributing to the development of creative potential and creativity. The creative environment is characterised by V.A. Yasvin as the environment that is notable for a high inner motivational activity, emotional upheaval, positive optimistic attitude, respect of the human thought. Such an environment influences the activity of learning and transforming the surrounding world, openness, freedom of thoughts and actions, personal orientation to selfdevelopment and self-realization [13]. But the specific skills as an active position of the subject do not determine the possibility of creative success. In this regard, the creative environment, which defines the nature of young people interaction, is a necessary element of socio-emotional wellbeing and psychological safety of the social environment.

\section{Conclusion}

Social environment built on the principles of tolerance, creativity and interpersonal communication provides a student with the feeling of socio-emotional (psychosocial) well-being.

The stated psychological indices (subjective wellbeing, social tolerance, communication skills, creativity), their weight and satisfaction must be considered when designing the system of youth training and developing their social safety as a personal-professional quality. The presented data of analytical and experimental studies let us determine the directions which would allow finding the ways of improvement of the educational process organization in order to ensure socio-emotional wellbeing of students and social safety of society as a whole.

\section{Acknowledgment}

The publication was prepared within the framework of a research project supported by the Russian State Humanitarian Fund №16-36-01088.

\section{References}

1. N.A. Knyazeva, A.G. Gryaznukhin, P.A. Kislyakov, V.I. Esaulov, Yu.I. Kekteeva \& Z.V. Polivara, International Review of Management and Marketing, 6(1), (2016)

2. V.V. Abramenkova \& A.S. Minyaev, Psychology in Russia: state of the art, 5, (2012)

3. N. Noddings. Happiness and education (New York, Cambridge University Press, 2003)

4. D. Stokols, Amer. psychologist, 50(10), (1995)

5. T.I. Kulikova, Psychology in Russia: State of the Art, 5, (2012)

6. P.A. Kislyakov, E.A. Shmeleva \& S.N. Tolstov, Voprosy psikhologii, 5 (2015)

7. Yu.P. Zinchenko, Psychology in Russia: state of the art, 4, (2011)

8. E.A. Shmeleva, P.A. Kislyakov, L.F. Luneva \& L.D. Maltseva, Psychology in Russia: State of the Art, 8(1), (2015)

9. E. Huebner \& R. Gilman, Applied Quality of Life Research, 1(2), (2006)

10. S. Suldo, E. Shaffer \& K. Riley, School Psychology Quarterly, 23(1), (2008) 
11. I.A. Baeva, \& N.V. Bordovskaia, Psychology in Russia: State of the Art, 8(1), (2015)

12. P.A. Kislyakov, E.A. Shmeleva, T.V. Karaseva \& O.A. Silaeva, Asian Social Science, 10(17), (2014)

13. V.A. Yasvin, Psikhologicheskii Zhurnal, 21(4), (2000) 